\title{
Spectral signatures of fluorescence and light absorption to identify crude oils found in the marine environment
}

\author{
E. Baszanowska \\ eba@am.gdynia.pl
}

\section{Z. Otremba}

Gdynia Maritime University, Physics Department, Gdynia, 81225, Poland

Gdynia Maritime University, Physics Department, Gdynia, 81225, Poland

To protect the natural marine ecosystem, it is necessary to continuously enhance knowledge of environmental contamination, including oil pollution. Therefore, to properly track the qualitative and quantitative changes in the natural components of seawater, a description of the essential spectral features describing petroleum products is necessary.

This study characterises two optically-different types of crude oils (Petrobaltic and Romashkino) - substances belonging to multi-fluorophoric systems. To obtain the spectral features of crude oils, the excitation-emission spectroscopy technique was applied. The fluorescence and light absorption properties for various concentrations of oils at a stabilised temperature are described. Both excitation-emission spectra (EEMs) and absorption spectra of crude oils are discussed. Based on the EEM spectra, both excitation end emission peaks for the wavelengthindependent fluorescence maximum $\left(E x_{\max } / E m_{\max }\right)$ - characteristic points for each type of oil - were identified and compared with the literature data concerning typical marine chemical structures.

[DOI: http://dx.doi.org/10.2971/jeos.2014.14029]

Keywords: Excitation-emission spectra, fluorescence spectroscopy, absorption spectra, oil pollution, seawater

\section{INTRODUCTION}

The implementation of sanctions for oil spills to meet the requirements of the protection of the marine environment has led to a significant decrease in registered oil spills [1]. For example, as the Baltic Sea Now Info reported, since 2006 the number of oil spills in the Baltic Sea has been reduced by half [2]. Moreover, in recent times there has been a significant increase in the intensity of maritime transport, which has led to an increased risk of an oil spill as a consequence of possible marine accidents. Therefore, it is worth broadening the scope of rapid detection to determine the source of the oil leak as well as identify the perpetrator.

Crude oil and petroleum products are highly complex mixtures of mainly hydrocarbon compounds [3]. The complex structure of petroleum products requires the application of the most sensitive techniques possible. To expand the knowledge of petroleum products, various techniques based on $U V$ visible, Infrared, Raman spectroscopy or chromatography have been used [4]-[8]. However, from among the various techniques, the most efficient method for highly complex structures seems to be fluorescence $[9,10]$ due to its high sensitivity.

Initially, petroleum products were studied based on fluorescence by Franck [11]. Since that time, there has been increased interest in the study of oils based on fluorescence methods for satellite, laboratory and in situ measurements [12]-[17]. However, the difficulty of the task lies in identifying the oil spill with the lowest concentration of oil. Many of these techniques, particularly satellite remote sensing measurements, allow oil pollution to be detected with large oil spills. In contrast, remote sensing techniques based on laser fluorescence (denoted as the LIDAR technique) which allow oil detection for low concentrations, are burdened by many technical problems which appear as limitations [18]-[20]. The problems of oil detection when the concentration of hydrocarbon compounds is low were reported by Dolenko et al. [15]. They noted the difficulty of separating an oil's fluorescence from humic compound fluorescence for concentrations of oil in the order of micrograms per kilogram. When detecting oil in low concentrations, excitation-emission fluorescence, synchronous fluorescence as well as fluorescence for single wavelength excitation can be considered. Work to expand the knowledge of the fluorescence of petroleum substances is still ongoing. For example, our studies are focused on collecting the shapes of fluorescence spectra for different types of oil in various oil-water systems [21, 22].

In order to protect the marine environment ecosystem, it is necessary keep track of the periodic dynamic changes in the presence of long-time natural components of seawater, such as chlorophyll, phytoplankton or coloured dissolved organic matter denoted as CDOM. A description of particular seawater component properties has been sought for many years. To solve this problem, many techniques were developed to detect and identify the changes of natural seawater components. Many of these techniques were based on fluorescence spectroscopy. It is well-known that natural surface waters, 
due the specific composition mentioned above, show a typical spectrum for those components. These components exhibit both fluorescence and absorption characteristics for appropriate excitation and emission wavelengths. Coble et al. described the absorption spectrum as well as fluorescence spectra based on excitation-emission spectra (EEMs) [23]-[25]. In many papers, specific points described as the typical fluorescence peaks for CDOM were presented. The spectral position of these peaks varies for both inshore and offshore waters, for rivers and estuaries and varies per season [26, 27]. The seawater fluorescence studies show that CDOM absorption is partially covered by chlorophyll absorption. These studies have been carried out mainly to expand knowledge about the natural ecosystem of the marine environment. Furthermore, these data on seawater components could allow remote sensing measurements based on optical methods to be applied to ocean colour systems or satellite measurements [24].

In order to conduct studies into protecting natural seawater ecosystems, studies of oils are also necessary. The information about the influence of oil presence on the light field transformation in the water column allow to complete the data to improve the operational models using in remote tracking the natural constituents of marine water (CDOM, phytoplankton or chlorophyll). Studies on petroleum substances indicate that they demonstrate fluorescence as well as significant absorbance in an area where chlorophyll or CDOM strongly absorbs light radiation [21, 22, 28].

In this paper, we present the excitation-emission spectra and absorption spectra for two types of crude oils, Petrobaltic and Romashkino. We consider Petrobaltic crude oil naturally present in the Baltic Sea in the Polish Exclusive Economic Zone and Romashkino crude oil from Tatarstan (Russia) to characterise and compare crude oils. Moreover, applied two types of oils were selected as radically different in their optical properties namely: Petrobaltic represents most bright and transparent oils, whereas Romashkino - dark and opaque ones. These spectra were determined for different concentration of oils, which allows the wavelength-independent fluorescence maximum and absorption coefficients of the oils in the ultraviolet wavelength range and typical features for these oils to be determined. This indicates that the results of measurements (presented later), such as specific oil absorption and fluorescence, can be compiled into a database to construct a profile of an oil's optical properties.

\section{MATERIAL AND METHOD}

\subsection{0il in $n$-hexane samples}

To prepare oil samples, two crude oils were used: Petrobaltic, extracted from the Baltic Sea in the Polish Exclusive Economic Zone, and Romashkino, extracted at the Romashkino field in Tatarstan (Russia). Visually, Petrobaltic is relatively clear and transparent compared to Romashkino, which is decidedly opaque. As a solvent, $n$-hexane (for analysis, $96.0 \%$ purity) was applied. Next, the base (stock solution) samples of oil in $n$-hexane for both types of oil were prepared. Based on

\begin{tabular}{|c|c|c|}
\hline Petrobaltic (P) & Romashkino (R) & $\begin{array}{c}c \\
{[\mathbf{m g} / \mathbf{k g}]}\end{array}$ \\
\hline P1 & R1 & 20 \\
\hline P2 & R2 & 50 \\
\hline P3 & R3 & 230 \\
\hline P4 & R4 & 280 \\
\hline
\end{tabular}

TABLE 1 Concentration of oil in $n$-hexane for considered oils.

this dilution method, four individual concentrations for both types of oil were prepared and are presented in Table 1.

\subsection{Measurement and apparatus}

Three-dimensional EEM spectra and the absorbance spectra of oil in n-hexane samples for both types of oil were obtained with an Aqualog Horiba spectrofluorometer [29]. The EEMs and absorbance spectra of oil in $n$-hexane samples were measured simultaneously [17]. Both EEM and absorbance spectra for all solutions were measured in a $1 \times 1 \mathrm{~cm}$ quartz cuvette.

For EEMs measurements, the following measurement parameters were applied: excitation wavelength from $240 \mathrm{~nm}$ to $600 \mathrm{~nm}$ with a $5 \mathrm{~nm}$ sampling interval, emission wavelength from $212.75 \mathrm{~nm}$ to $622.97 \mathrm{~nm}$ with a $1.623 \mathrm{~nm}$ sampling interval, $5 \mathrm{~nm}$ excitation slit, $5 \mathrm{~nm}$ emission slit and $1 \mathrm{~s}$ integration time.

For absorbance spectra measurements, the following parameters were applied: excitation wavelength from $240 \mathrm{~nm}$ to $600 \mathrm{~nm}$ with $5 \mathrm{~nm}$ sampling interval, $5 \mathrm{~nm}$ slit and $1 \mathrm{~s}$ integration time. It is worth noting that the absorbance spectra were measured from the longest to the lowest excitation wavelength because of the technical features of this spectrofluorometer.

The software package of the spectrofluorometer allows automatic removal of Raman and Rayleigh scattering [29], to yield a digital matrix of excitation-emission spectra.

\section{RESULTS}

\subsection{Fluorescence}

EEM spectra for the two crude oils diluted in n-hexane for four concentrations at a stabilised temperature of $20^{\circ} \mathrm{C}$ were determined. Figure 1 presents the fluorescence spectra in three-dimensional planes (3D spectra) for two concentrations of crude oils. Significant changes of fluorescence intensity of the main peak of EEMs caused by oil concentration are more visible for Petrobaltic (P1, P4) than for Romashkino (R1, R4).

To observe the pure shapes of spectra changes (excluding intensity), the excitation-emission matrices were normalized to the maximal values. The tendencies to transform spectra caused by changes in oil concentration are shown in Figure 2.

In Figure 2, for Romashkino crude oil, the following effect resulting from the dilution of the oil solution was observed: when the concentration of oil increases, the wavelength of 

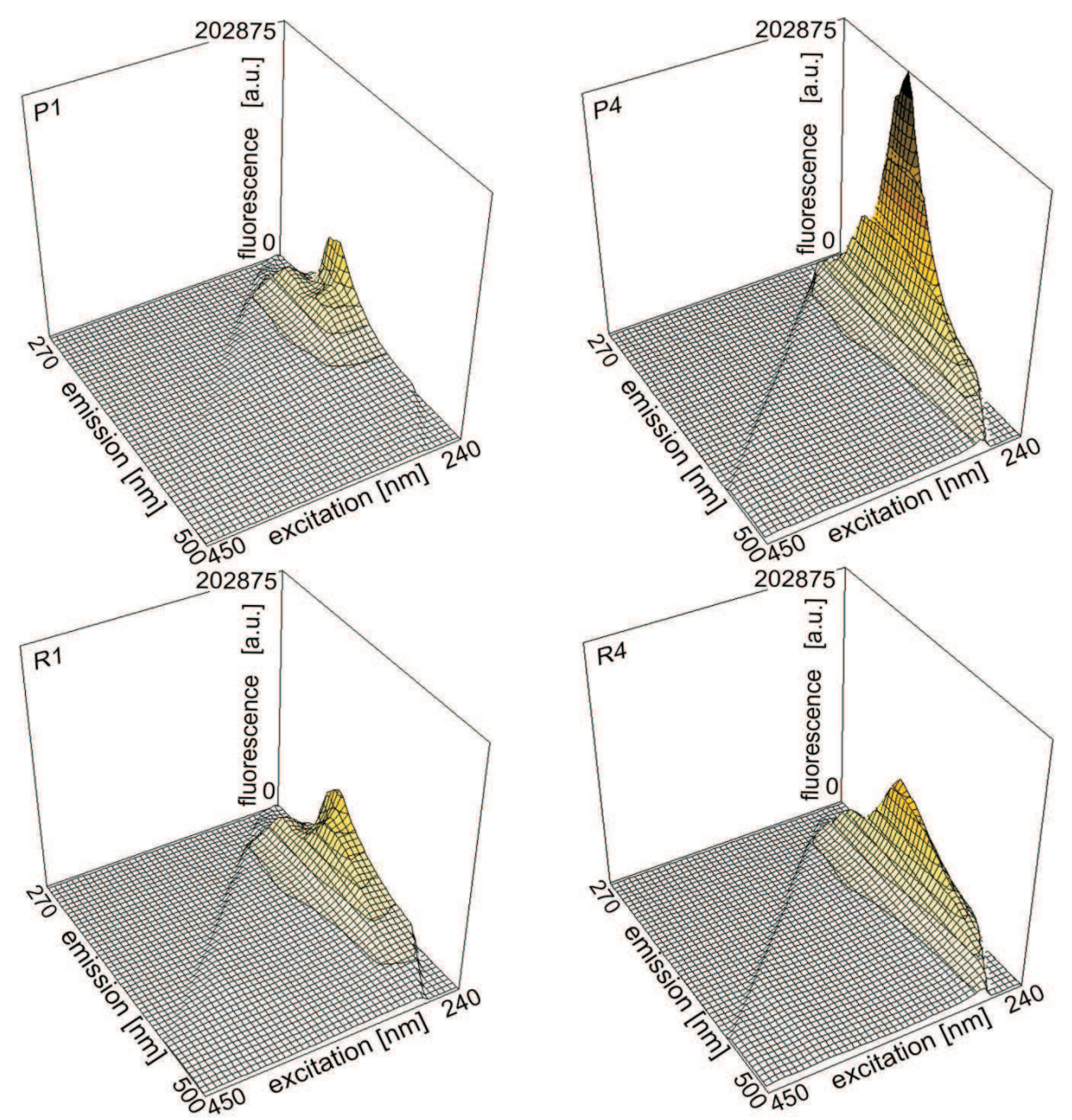

FIG. 1 Excitation-emission fluorescence spectra (EEMs) of oil in hexane dilutions for Petrobaltic (P) and Romashkino (R) crude oil, in two oil concentrations (P1, R1: 20 mg/kg, P4, R4: $280 \mathrm{mg} / \mathrm{kg})$.

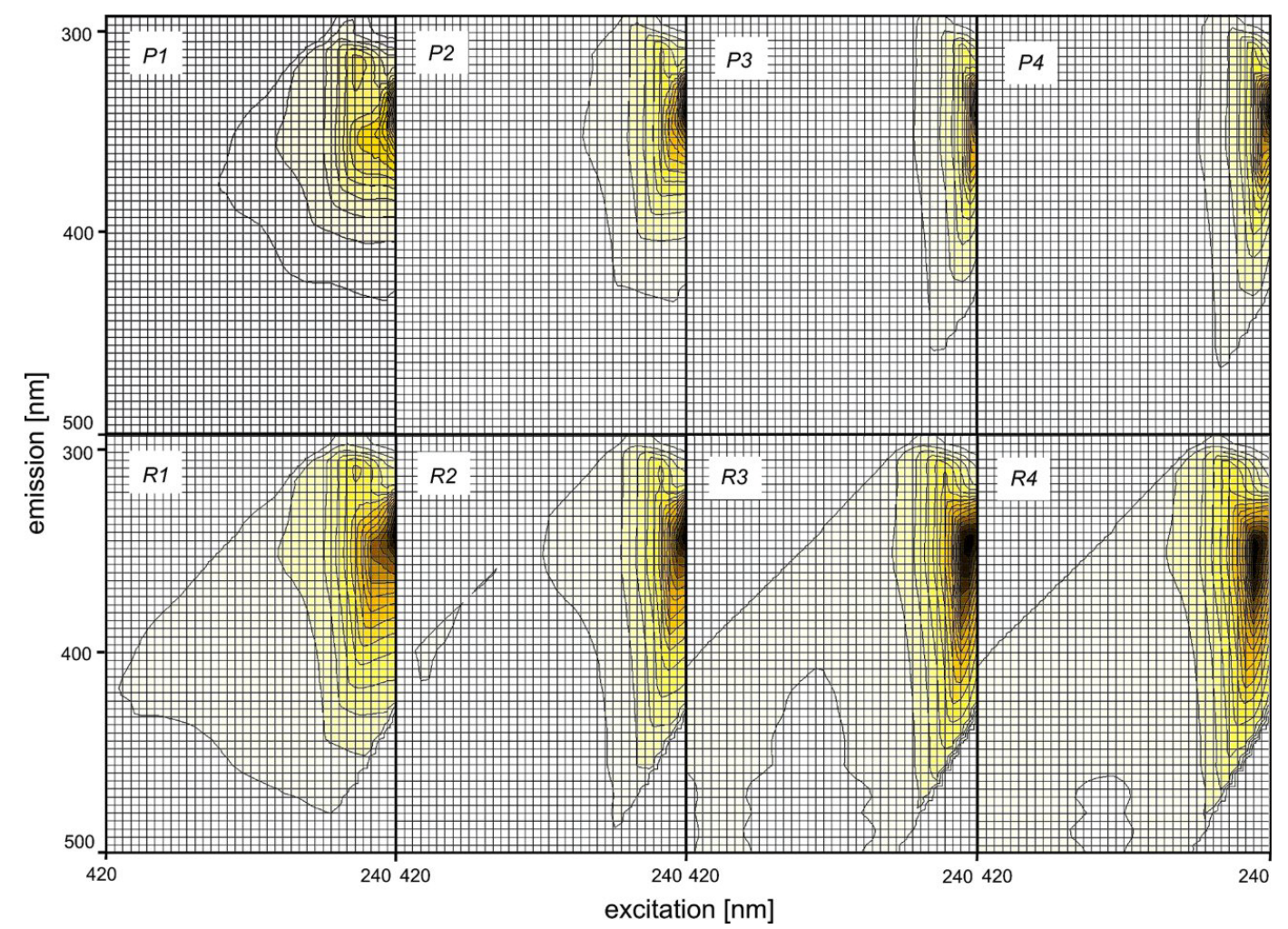

FIG. 2 Transformation of normalized EEMs for Petrobaltic (P) and Romashkino ( $\mathrm{R}$ ) crude oil with oil concentration in $n$-hexane (1: $20 \mathrm{mg} / \mathrm{kg}$, $2: 50 \mathrm{mg} / \mathrm{kg}, 3: 230 \mathrm{mg} / \mathrm{kg}$, 4: $280 \mathrm{mg} / \mathrm{kg}$ ). 


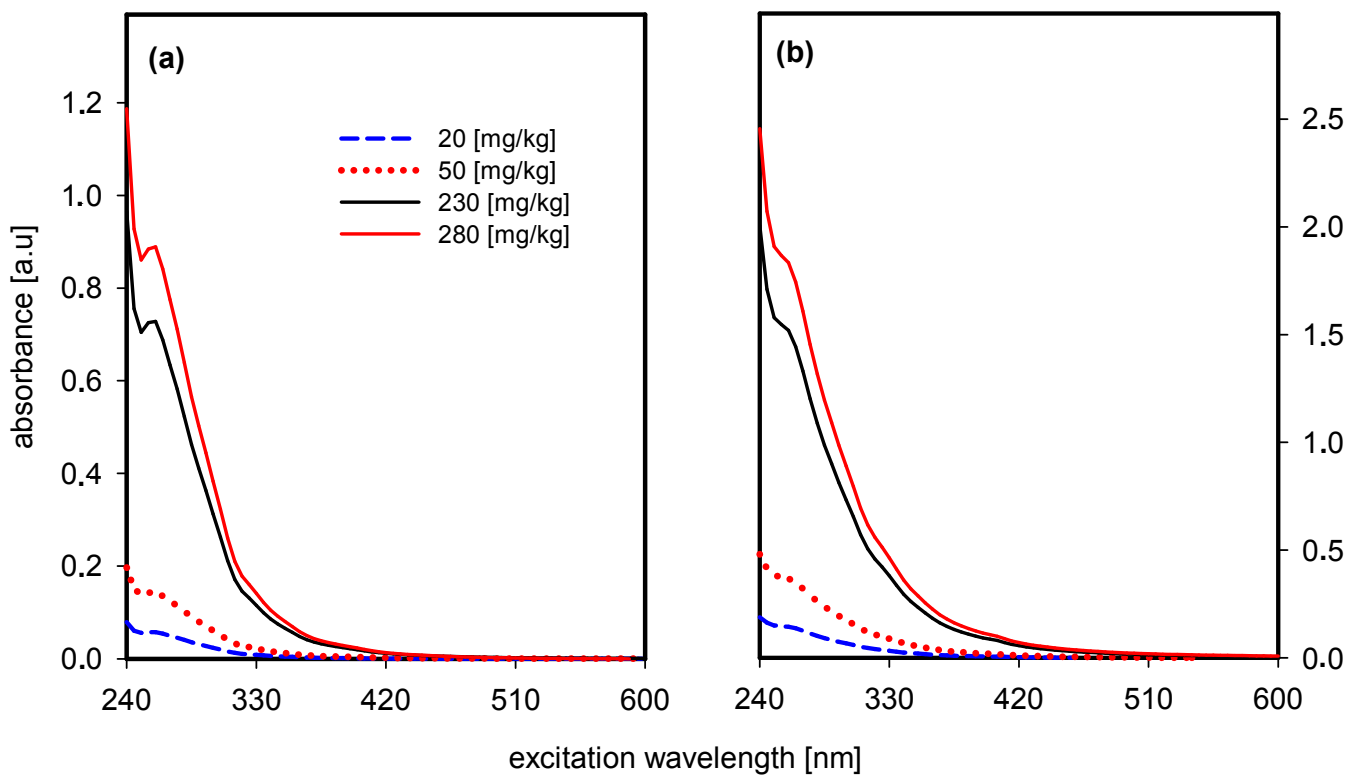

FIG. 3 Absorption spectra of oil in $n$-hexane for Petrobaltic (a), Romashkino (b) for various oil concentrations.

\begin{tabular}{|c|c|c|c|}
\hline \multicolumn{2}{|c|}{ Petrobaltic } & \multicolumn{2}{c|}{ Romashkino } \\
\hline E $\boldsymbol{x}_{\text {max }} \pm \mathbf{5}[\mathbf{n m}] /$ Em $_{\max } \pm \mathbf{5}[\mathbf{n m}]$ & \multicolumn{2}{|c|}{$\boldsymbol{x}_{\text {max }} \pm \mathbf{5}[\mathbf{n m}] /$ Em $_{\max } \pm \mathbf{5}[\mathbf{n m}]$} \\
\hline P1 & $240 / 350$ & R1 & $240 / 350$ \\
\hline P2 & $240 / 350$ & R2 & $240 / 350$ \\
\hline P3 & $240 / 350$ & R3 & $245 / 358$ \\
\hline P4 & $240 / 350$ & R4 & $250 / 360$ \\
\hline
\end{tabular}

TABLE 2 The values for wavelength-independent fluorescence properties of oil fluorescence peak: excitation maximum ( $E x_{\max }$ ), emission maximum ( $E m_{\max }$ ).

maximum fluorescence intensity starts from near $350 \mathrm{~nm}$ and moves to $360 \mathrm{~nm}$, while the excitation wavelength related to the maximum fluorescence intensity starts from $240 \mathrm{~nm}$ and increases to the $250 \mathrm{~nm}$. The results indicate that for Romashkino with dilution there are shifts to longer emission wavelengths (red shift). However, for Petrobaltic crude oil, the intensity of maximum fluorescence increases when the concentration of oil increases, although excitation and emission wavelengths related to fluorescence maximum remain constant.

The shape of fluorescence spectra demonstrates the presence of peaks, typical for two kinds of crude oil. Based on EEMs, the peaks typical for both oils can be described by the specific wavelengths: excitation and emission - described as the peak position of wavelength-independent fluorescence maximum, written as $E x_{\max } / E m_{\max }$. The specific peaks described as wavelength-independent were determined for both kinds of oil for various oil concentrations. The values of wavelengthindependent fluorescence maximum are presented in Table 2. The permanent value of this parameter was observed for different concentrations for Petrobaltic oil. In contrast, for Romashkino oil, a shift in the wavelength-independent fluorescence maximum to the longer wavelengths was observed with an increase in oil concentration. Taking into account the variations of the wavelength-independent fluorescence maximum, the range of changes of these parameters for both types of oil was determined. Table 3 presents the range of wavelengthindependent fluorescence maximums for the studied oils.

\begin{tabular}{|c|c|}
\hline & $E x_{\max } \pm \mathbf{5}[\mathbf{n m}] / \boldsymbol{E m}_{\max } \pm \mathbf{5}[\mathbf{n m}]$ \\
\hline Petrobaltic & $240 / 350$ \\
\hline Romashkino & $240-250 / 350-360$ \\
\hline
\end{tabular}

TABLE 3 The range of values for wavelength-independent fluorescence properties of oil fluorescence peak: excitation maximum $\left(E x_{\max }\right)$, emission maximum $\left(E m_{\max }\right)$.

The results of EEMs for Petrobaltic and Romashkino show that these oils display fluorescence in the ultraviolet range and the maximum fluorescence of oils depends on the type of oil. The maximum excitation wavelength changes from $240 \mathrm{~nm}$ to $250 \mathrm{~nm}$ and the maximum emission wavelengths changes from $350 \mathrm{~nm}$ to $360 \mathrm{~nm}$.

\subsection{Absorbance}

Absorbance spectra $A(\lambda)$ were registered simultaneously to the excitation-emission spectra (EEMs) using an Aqualog Horiba spectrofluorometer. The measurement principle is based on the following rule (Eq. (1)) [14]:

$$
A(\lambda)=-\log \left(\frac{I(\lambda)}{I_{0}(\lambda)}\right)
$$

and $I_{0}(\lambda), I(\lambda)$ describe, respectively, the intensity of the light that has passed through the reference sample ( $n$-hexane) and the intensity of the light that has passed through the oil in $n$ hexane sample.

Figure 3 presents the absorbance spectra registered for crude oils Petrobaltic and Romashkino, for various oil concentrations 
(the same as in EEMs measurements). The absorbance spectra achieved higher values for crude oil Romashkino. The absorbance spectra show strong changes in the wavelength range from $240 \mathrm{~nm}$ to $420 \mathrm{~nm}$, while for the longer wavelengths remain at the same level and takes relatively low values.

\section{DISCUSSION}

The solution to the problem of recognising the individual constituents of seawater which influence the excitation-emission spectra plays an important role in the process of finding the easiest and most efficient method for detection and quantification of natural and alien substances in the seawater. In this paper, a potential component of the seawater - crude oil is considered. Since crude oils and their derivatives contain fluorescence compounds (mainly cyclic and polycyclic hydrocarbons), they may disturb methods of determining various seawater constituents and, conversely, various natural seawater constituents may disturb the detection of oil substances in the sea environment. Coble [24] revealed characteristic indices extracted from EEMs that are assigned to define groups of compounds typical for the aquatic environment. The mentioned author describes the peaks of EEM spectra typical for CDOM [23]-[25]. These peaks were described for particular components of CDOM, such as aminoacid-like humic acids and fulvic acids. Taking into account the EEM spectra presented in this paper, as well as the determined value of independent-wavelength of fluorescence maximum of oils, it can be seen that the maximum excitation wavelength of oil can be located in the region of the excitation wavelength for CDOM - especially for tryptophan-like or protein-like, as well as humic-like. At the same time, the author noted the role of the origin of particular types of compounds.

All of the above indicates that oil pollution in the marine environment can strongly disturb the possibility of florescence and absorption of typical components of natural seawater. In consequence, it leads to the variations in EEMs or the absorption spectra of natural seawater. In the future, it would be interesting to track the excitation-emission spectra and absorption spectra of oils belonging to other groups of oils (i.e. lubricate oils, fuels) to expand knowledge about the spectral properties of oils. A comparison of the wavelength-independent fluores-

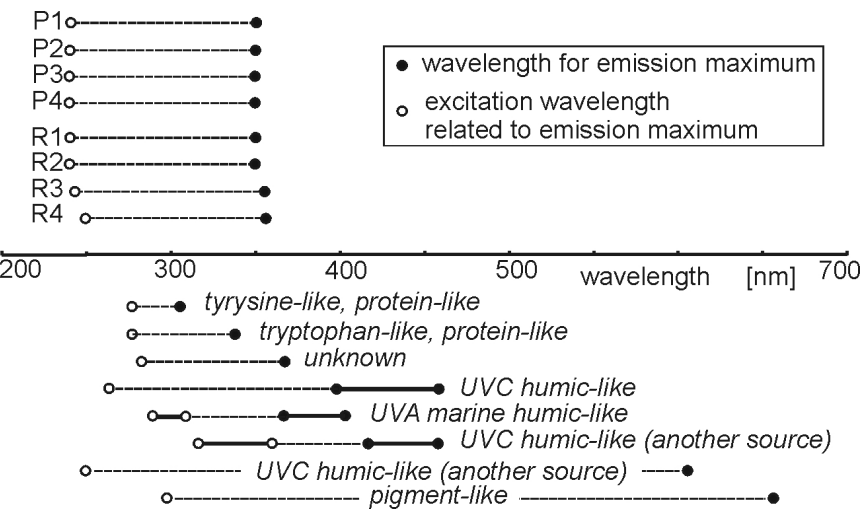

FIG. 4 Juxtaposition of crude oils with various marine constituents (described in paper [24]) in respect of $E x_{\max } / E m_{\max }$ cence $E x_{\max } / E m_{\max }$ of crude oils (Table 2) with various marine constituents [24] is given in Figure 4. This diagram shows that the highest points indicating $E m_{\max }$ are located at wavelengths longer than for oils. At the same time, points indicating $E x_{\max }$ correspond to the longer wavelengths in every case. This observation can be treated as an advantage for distinguishing the oil-origin part of EEMs from other areas of EEMs connected with the natural seawater constituents. The other advantage is that the indexes $E x_{\max } / E m_{\max }$ for oil almost do not depend on the concentration or type of oil.

On the other hand, if the entire area of EEMs are considered in respect to their similarities, the concentration of oil influences the similarity ratio $S_{\mathrm{ab}}$ (Eq. (2)) in low concentrations, whereas in higher concentrations the similarity ratio is independent of oil concentration (Figure 5). The similarity ratio $S_{\mathrm{ab}}$ between the fluorescence spectra of the two oil solutions for the considered concentration of oils is given by Eq. (2) (as used in the paper [17]). In this formula, the indexes "ij" refer to relative columns and rows in tables representing spectra " $\mathrm{a}$ " and " $\mathrm{b}$ ", the quantities $w_{i j}^{a}$, $w_{i j}^{b}$ refer, respectively, to normalised elements of EEM matrix of reference oil solution " $a$ " and compared solution " $\mathrm{b}$ ".

$$
S_{a b}=1-\frac{\sum_{i j}\left|w_{i j}^{a}-w_{i j}^{b}\right|}{\sum_{i j} w_{i j}^{a}}
$$

It is possible that supporting measurements using the same device (as for fluorescence), i.e. absorbance spectra, will improve the methodology of spectral measurements of seawater constituents. Based on measured absorbance $A(\lambda)$, the absorption coefficients $a(\lambda)$ for considered concentrations of oils were determined as follows:

$$
a(\lambda)=\frac{2.303 A(\lambda)}{c d}
$$

where $A(\lambda)$ - above-mentioned absorbance and $c, d$ describe,

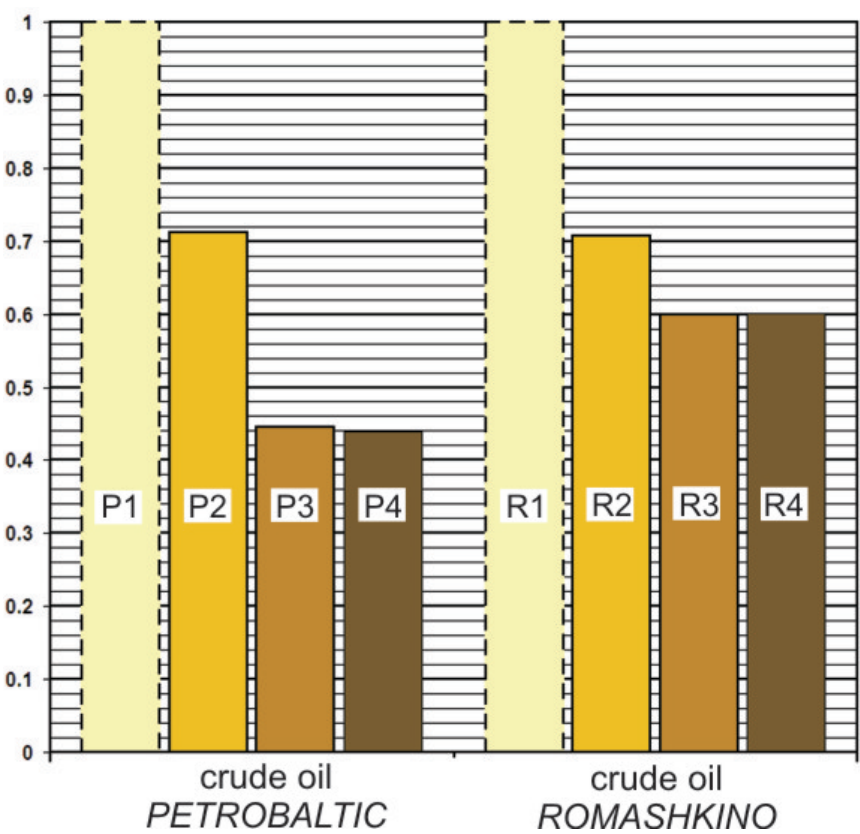

FIG. 5 The decrease in the similarity ratio of spectra for various oil concentrations (as in Figure 2) related to the lowest concentration. 


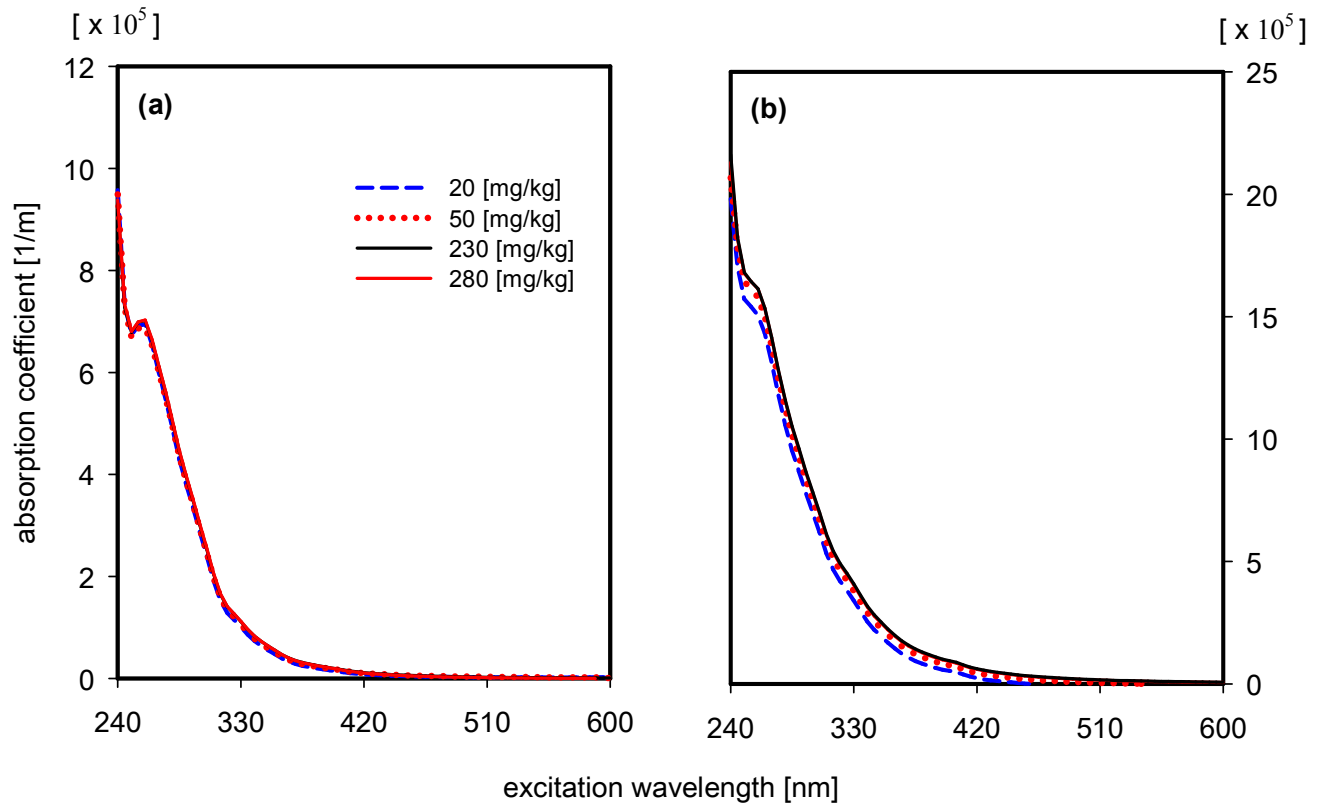

FIG. 6 Absorption coefficient of oil in $n$-hexane for Petrobaltic (a), Romashkino (b) for various oil concentrations (derived using Eq. (3) based on data depicted in Figure 3).

respectively, the concentration index of the oil solution expressed in kilograms of oil per one kilogram of $n$-hexane solution and the cuvette length.

Figure 6 presents values of absorption coefficient changes in considered excitation wavelength. The obtained values of absorbance (Figure 3) and absorption coefficient (Figure 6) for considered crude oils indicate that Romashkino crude oil displayed higher predisposition for absorption. Moreover, the absorption coefficients for Petrobaltic and Romashkino also change in the wavelength range from $240 \mathrm{~nm}$ to $420 \mathrm{~nm}$. For Petrobaltic crude oil in Figure 6, there is a sharp absorption peak for wavelength $260 \mathrm{~nm}$. In contrast, for Romashkino oil, the absorption spectrum is rather monotonic and the plane peak is observed near $260 \mathrm{~nm}$.

\section{CONCLUSION}

The here presented spectral features of crude oils based on Petrobaltic and Romashkino crude oils will facilitate a quick and easy oil pollution determination in natural waters. Moreover, this knowledge is also essential for changes in CDOM or chlorophyll monitoring in surface seawater threatened by the presence of oil substances. In the future, the data could be used for modelling the upward/downward light fluxes in the water column as well as upward fluxes above the sea surface or help to expand knowledge of fluorescence to aid the search for an effective fluorosensor to detect oil pollution suspended in a water column [30].

In the future activities are envisaged to create a database of EEM spectra for typical oils potentially found in the marine environment. One can assume that the EEMs data of oil could be used as the patterns for oils identifying in the natural marine environment based on model heretofore taking into account only typical constituents of the natural marine water.

\section{ACKNOWLEDGEMENTS}

This paper was partially supported by Gdynia Maritime University grant No. 360/DS/2014 and No. 06/BMN/M/2014. We would like to thank Oliver Zielinski for helping Emilia Baszanowska to arrange research at Marine Sensor Systems (ICBM), University Oldenburg in Wilhelmshaven, where the measurements were performed. We would like to especially thank Henryk Toczek for his help in preparing the samples.

\section{References}

[1] M. Fingas, The Basics of Oil Spill Cleanup (CRC Press Taylor at Francis Group, Boca Raton, 2013).

[2] http://balticseanow.turkuamk.fi/index.php/ the-number-of-oil-spills-down-to-half-in-the-baltic-sea/

[3] C. D. Geddes, and J. R. Lakowicz (eds.), Reviews in Fluorescence 2005 (Springer, New York, 2005).

[4] T. D. Downare, and 0. C. Mullins, "Visible and near-infrared fluorescence of crude oils," Appl. Spectrosc. 49, 754-764 (1995).

[5] M. Fingas, and C. Brown, Review of oil spill remote sensors (Seventh International Conference on Remote Sensing for Marine and Coastal Environments, Miami, 20-22 May 2002).

[6] Z. Wang, and S. Stout, Oil Spill Environmental Forensics: Fingerprinting and Source Identification (Elsevier, Boston, 2007).

[7] N. Skou, B. Sorensen, and A. Poulson, "A new airborne dual frequency microwave radiometer for mapping and quantifying mineral oil on the sea surface, in Proceedings to the Second Thematic Conference on Remote Sensing for Marine and Coastal Environments, II559-II565 (ERIM Conferences, Ann Arbor, 1994).

[8] 0. Zielinski, J. A. Busch, A. D. Cembella, K. L. Daly, J. Engelbrektsson, A. K. Hannides, and H. Schmidt, "Detecting marine hazardous substances and organisms: sensors for pollutants, toxins and pathogens," Ocean Sci. 5, 329-349 (2009).

[9] J. Bublitz, A. Christophersen, and W. Schade, "Laser-based detection of PAHs and BTXE aromatics in oil polluted soil samples," Fresenius J. Anal. Chem. 355, 684-686 (1996). 
[10] J. Bublitz, and W. Schade, "Multiwavelength laser-induced fluorescence spectroscopy for quantitative classification of aromatic hydrocarbons," Proc. SPIE 2504, 265-277 (1995).

[11] U. Frank, "A review of fluorescence spectroscopic method for oil spill source identification," Toxicol. Environ. Chem. Rev. 2, 163-185 (1978).

[12] S. Patsayeva, "Fluorescent remote diagnostics of oil pollutions: oil in films and oil dispersed in the water body," EARSeL Adv. Remote Sens. 3, 170-178 (1995).

[13] L. Poryvkina, S. Babichenko, and 0. Davydova, "SFS characterisation of oil pollution in natural water," in Proceedings to 5 th International Conference on Remote Sensing for Marine and Coastal Environments, 520-524 (Michican Tech Research Institute, San Diego, 1998).

[14] E. Baszanowska, and Z. Otremba, "Spectroscopic methods in application to oil pollution detection in the sea," J. KONES 19, 15-20 (2012).

[15] T. A. Dolenko, V. V. Fadeev, I. V. Gerdova, S. A. Dolenko, and R. Reuter, "Fluorescence diagnostics of oil pollution in coastal marine waters by use of artificial neural networks," Appl. Opt. 41, 5155-5166 (2002).

[16] H. Visser, "Teledetection of the thickness of oil films on polluted water based on the oil fluorescence properties," Appl. Opt. 18, 1746-1749 (1979).

[17] E. Baszanowska, 0. Zielinski, Z. Otremba, and H. Toczek, "Influence of oil-in-water emulsions on fluorescence properties as observed by excitation-emission spectra," J. Europ. Opt. Soc. Rap. Public. 8, 13069 (2013).

[18] R. Karpicz, A. Dementjev, Z. Kuprionis, S. Pakalnis, R. Westphal, R. Reuter, and V. Gulbinas, "Oil spill fluorosensing lidar for inclined onshore or shipboard operation," Appl. Opt. 45, 6620-6625 (2006).

[19] J. Vasilescu, L. Marmureanu, E. Carstea, and C. P. Cristescu, "Oil spills detection from fluorescence lidar measurements," U. P. B. Sci. Bull., Series A 72, 149-154 (2010).

[20] A. G. Abroskin, S. E. Nol'de, V. V. Fadeev, and V. V. Chubarov, "Laser fluorimetry determination of emulsified-dissolved oil in water," Sov. Phys. Dokl. 33, 215-217 (1988).
[21] E. Baszanowska, Z. Otremba, H. Toczek, and P. Rohde, "Fluorescence spectra of oil after it contacts with aquatic environment," J. KONES 20, 29-34 (2013).

[22] Z. Otremba, E. Baszanowska, H. Toczek, and P. Rohde, "Spectrofluorymetry in application to oil-in-water emulsion characterization," J. KONES 18, 317-321 (2011).

[23] P. G. Coble, "Characterization of marine and terrestrial DOM in seawater using excitation-emission matrix spectroscopy," Mar. Chem. 51, 325-346, (1996).

[24] P. G. Coble, "Marine optical biogeochemistry: the chemistry of ocean color," Chem. Rev. 107, 402-418 (2007).

[25] P. G. Coble, "Colored dissolved organic matter in seawater," in Subsea Optics and Imaging, J. Watson, and 0. Zielinski, eds., 98-118 (1st edition, Woodhead Publishing, Cambridge, 2013).

[26] V. Drozdowska, W. Freda, E. Baszanowska, K. Rudź, M. Darecki, J. Heldt, and H. Toczek, "Spectral properties of natural and oil polluted Baltic seawater - results of measurements and modelling," Eur. Phys. J. Special Topics 222, 2157-2170 (2013).

[27] P. Kowalczuk, J. Stoń-Egiert, W. J. Cooper, R. F. Whitehead, and M. J. Durako, "Characterization of chromophoric dissolved organic matter (CDOM) in the Baltic Sea by excitation emission matrix fluorescence spectroscopy," Mar. Chem. 96, 273-292 (2005).

[28] J. H. Christensen, A. B. Hansen, J. Mortensen, and 0. Andersen, "Characterization and matching of oil samples using fluorescence spectroscopy and parallel factor analysis," Anal. Chem. 77, 22102217 (2005).

[29] Operation manual, Aqualog Horiba, rev. A (Horiba Scientific, 2011).

[30] R. N. Conmy, P. G. Coble, J. Farr, A. M. Wood, K. Lee, W. S. Pegau, I. D. Walsh, et al.,"Submersible optical sensors exposed to chemically dispersed crude oil: wave tank simulations for improved oil spill monitoring," Environ. Sci. Technol. 48, 1803-1810 (2014). 